\title{
MOSQUITO BIODIVERSITY PATTERNS AROUND URBAN ENVIRONMENTS IN SOUTH-CENTRAL OKINAWA ISLAND, JAPAN
}

\author{
TOMONORI HOSHI, ${ }^{1,2}$ NOZOMI IMANISHI, ${ }^{2}$ YUKIKO HIGA ${ }^{2}$ AND LUIS FERNANDO CHAVES ${ }^{2,3,4}$
}

\begin{abstract}
Okinawa is the largest, most urbanized, and densely populated island in the Ryukyus Archipelago, where mosquito species diversity has been thoroughly studied. However, the south-central Okinawa mosquito fauna has been relatively poorly studied. Here, we present results from a mosquito faunal survey in urban environments of Nishihara city, south-central Okinawa. Mosquitoes were sampled biweekly, from April 2007 to March 2008, at 3 different environments: a forest preserve, an animal farm, and a water reservoir. We employed 4 mosquito collection methods: 1) oviposition traps; 2) light traps; 3) sweep nets; and 4) larval surveys of tree holes, leaf axils, and artificial water containers. We collected a total of 568 adults and 10,270 larvae belonging to 6 genera and 13 species, including 6 species of medical importance: Aedes albopictus, Armigeres subalbatus, Anopheles Hyrcanus group, Culex bitaeniorhynchus, Cx. quinquefasciatus, and $C x$. tritaeniorhynchus. Mosquito species composition was similar to data from previous studies in Okinawa Island. The flattening of the species accumulation curve suggests that our diversity sampling was exhaustive with light and oviposition traps, as well as the coincidence between the species richness we found in the field and estimates from the Chao 2 index, a theoretical estimator of species richness based on species abundance. This study highlights the importance of combining several sampling techniques to properly characterize regional mosquito fauna and to monitor changes in the presence of mosquito species.
\end{abstract}

KEY WORDS Mosquito biodiversity, mosquito fauna, Ryukyu Archipelago, Okinawa Island

\section{INTRODUCTION}

Mosquitoes have a rich biodiversity in tropical and subtropical regions (Foley et al. 2007). Okinawa, as the largest and most densely populated island in the subtropical Ryukyu Archipelago, consists of approximately 200 islands (Ota 1998). Several studies have shown the mosquito fauna of the Ryukyus to be extremely diverse (Miyagi 1976, Toma and Miyagi 1986, Miyagi et al. 1990, Okudo et al. 2004), with more than half of Japan's mosquito species present in the archipelago, which accounts for $<1 \%$ of Japan's territory (Toma 2002). The Ryukyu Archipelago islands are continental and were connected with East Eurasia during the last glaciation by means of a land bridge connecting the island of Kyushu to southeastern China via Taiwan (Ota 1998). It is likely that this complex history, a relatively stable subtropical climate, widespread natural vegetation, and the abundance and diversity of natural habitats underpin the extraordinary patterns of mosquito species diversity in the archipelago (Toma and Miyagi 1986).

Mosquitoes also are medically important insects since the discovery of their role as disease

${ }^{1}$ Entomological Laboratory, Faculty of Agriculture, University of the Ryukyus, Nishihara, Okinawa 9030213, Japan.

Institute of Tropical Medicine (NEKKEN), Nagasaki University, Nagasaki 852-8523, Japan.

${ }^{3}$ Programa de Investigación en Enfermedades Tropicales (PIET), Escuela de Medicina Veterinaria, Universidad Nacional, Apartado Postal 304-3000, Heredia, Costa Rica.

${ }^{4}$ To whom correspondence should be addressed. vectors and are one of the major nuisance pests worldwide (Silver 2008). Risk assessment and control of mosquito-borne diseases, as well as nuisance pest control, require a comprehensive knowledge of mosquito species diversity, and environmental factors, in and around human settlements (WHO 1975, Silver 2008). In some urban settings, mosquito diversity has been associated with arbovirus infection patterns (Chaves et al. 2011, Thongsripong et al. 2013). Currently, mosquito-borne diseases are rare in Japan (NIID 2010). Nevertheless, severe malaria and dengue outbreaks occurred in the Ryukyu Archipelago during World War II, and the vectors are still present (Miyagi et al. 1996, Toma et al. 2003). This highlights the vulnerability of this area to the introduction of vector-borne diseases. Studies that consider whole mosquito communities, beyond species with known vectorial roles, therefore have the potential to identify ecological interactions that may prove useful in controlling vector abundance and disease transmission (Chaves et al. 2011). For example, based on the ecological interactions of mosquitoes as part of ecological communities, one study evaluated natural mosquito predators as an ecologically sound method for vector control in Okinawa (Miyagi et al. 1992). This demonstrates the need for the ecological study of mosquito species, especially in urban environments where mosquito-borne diseases can emerge and/or mosquito nuisance might be considered an important issue.

In this study, we describe diversity patterns of mosquito species in the south-central part of Okinawa Island, where urban areas are embedded in highly forested environments. 


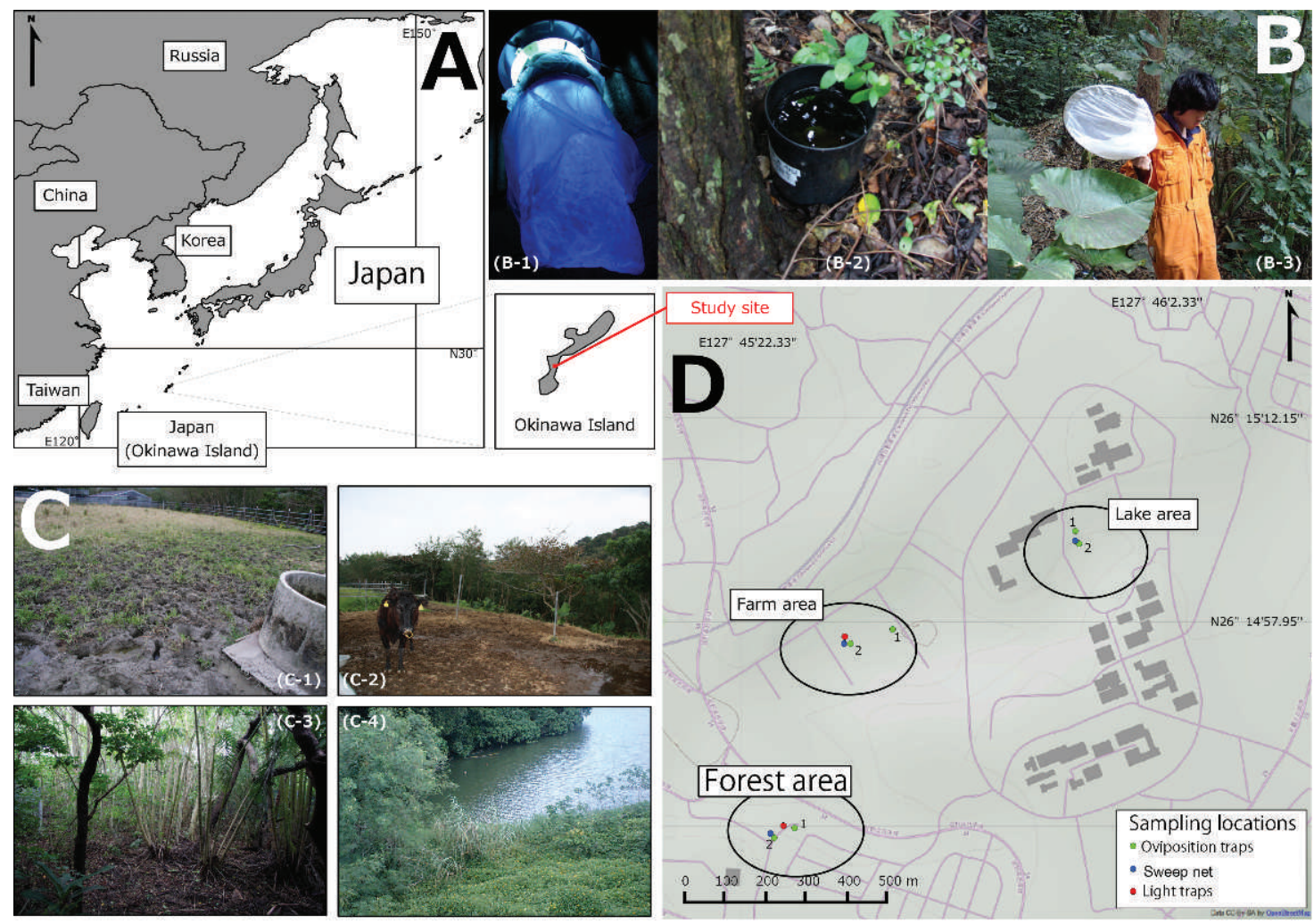

Fig. 1. Study locations in Okinawa Island and sampling methods. (A) Okinawa location in East Asia; (B) mosquito sampling methods: (B-1) light trap, (B-2) oviposition trap (ovitrap), and (B-3) sweep net; (C) sampling location habitats: (C-1) farm area where animals stay during the day, (C-2) farm area where animals stay during the night, (C-3) forest area, and (C-4) lake area; and (D) locations of each sampling method and habitats. Larval surveys of tree holes, leaf axils, and artificial containers were conducted near each ovitrap site.

\section{MATERIALS AND METHODS}

\section{Study site}

Mosquitoes were collected biweekly (i.e., every 2 wk) at the University of the Ryukyus campus, south-central Okinawa Island, from April 2007 to March $2008\left(26^{\circ} 26^{\prime} \mathrm{N}, 127^{\circ} 77^{\prime} \mathrm{E}\right)$. The University of the Ryukyus campus extends over $1,033 \mathrm{~m}^{2}$, and includes a forest, a lake, and a small animal farm. We selected sampling sites in each of these 3 habitats to consider habitat heterogeneity in an urban environment (Fig. 1). Briefly, the farm has several types of domestic animals: cows, goats, dogs, chickens, and rabbits. The animal farm sporadically had wild taro growing, which was systematically removed by the farm staff. The forest has a small stream; and the lake is a retention basin to prevent flooding with water present all year-round.

\section{Mosquito collection}

Mosquitoes were sampled with light traps (LTs), sweep nets (NSw), and oviposition traps (OTs). In addition, pipettes were occasionally used to suck the content from tree holes, leaf axils, and artificial containers near trap sites (OS). The LTs and NSw were used for adult collection, and OTs and OS for larval collection. Trap locations are shown in Fig. 1.

Light traps: Electrically operated LTs (Fig. 1; MC-8200; Ishizaki Electronic Manufacturing Co., Tokyo, Japan) powered by $30-\mathrm{W}$ ultraviolet fluorescent lights were placed 1 night every $2 \mathrm{wk}$ at $1.5 \mathrm{~m}$ above ground level and operated from $1600 \mathrm{~h}$ to $0800 \mathrm{~h}$ in the farm and forest sites (Hoshi et al. 2014). The lack of electricity sources prevented the use of LTs at the lake site. We selected this sampling period aiming to collect mosquitoes with day and night activity. Our traps had no dry ice. Mosquitoes collected were brought to the laboratory and killed by placing them in a refrigerator at low temperature $\left(-40^{\circ} \mathrm{C}\right)$ for $10 \mathrm{~min}$.

Sweep nets: Adult mosquitoes were also collected every 2 wk using a sweep net $(36-\mathrm{cm}$ diam; Model 61-B; Shiga Insect Co., Tokyo, Japan) (Miyagi and Toma 1980). Collections were made for $10 \mathrm{~min}$ between $1000 \mathrm{~h}$ and $1500 \mathrm{~h}$, near the OTs (Silver 2008). The collector did not 
actively sweep the vegetation to capture mosquitoes but rather stood at fixed points at each sampling site, collecting active mosquitoes. Mosquitoes collected were transferred into a vial with chloroform and subsequently put inside a plastic container ( $3 \mathrm{~cm}$ diam, $6 \mathrm{~cm}$ high; Fuji ${ }^{\circledR}$ Film roll case), using cotton to protect mosquitoes from damage before transporting them to the laboratory. The plastic tubes were placed in a freezer to kill any surviving mosquitoes.

Oviposition traps: Two black plastic buckets $(15 \mathrm{~cm} \times 20 \mathrm{~cm}, 3.53$ liters, dustbin; Daiso Co., Hiroshima, Japan) were filled with water (2.5 liters) and set on the ground (Fig. 1) near vegetation at each site (Hoshi et al. 2014). Although OTs are most frequently used to sample eggs (Reisen and Basio 1972, Chaves and Kitron 2011, Nguyen et al. 2012), we used ovitraps for larval collections (Moriya 1974). Each bucket had 2 holes at a height of $15 \mathrm{~cm}$ from the base to prevent flooding in the event of rain. The contents of the traps were transferred to a plastic tray $(37.4 \mathrm{~cm} \times 27.3 \mathrm{~cm} \times 6.4 \mathrm{~cm}, 4.6$ liters, Sanbat2gou; Sanko Co., Tokyo, Japan), and mosquito larvae were sieved and placed in vials $(7.5 \mathrm{~cm} \times 9.2 \mathrm{~cm}, 0.3 \mathrm{ml}$; 5-026-01; Sankoukasei Co., Osaka, Japan) before transporting them to the laboratory for enumeration and species identification. This procedure took an average of $20 \mathrm{~min}$ per trap and was performed in the morning from $0900 \mathrm{~h}$ to $1100 \mathrm{~h}$. Traps were continuously operated during the study, i.e., not removed.

Tree hole, leaf axil, and artificial container larval surveys: Tree holes, leaf axils, and artificial water containers near our OTs were sampled for mosquito larvae, using a 23-cm Komagome pipette (Komagome type pipette, $3 \mathrm{ml}$, Model 6275-03; Maruemu Co., Osaka, Japan). Mosquito larvae were transferred to a plastic container (3 $\mathrm{cm} \times 6 \mathrm{~cm}$, film roll case) for each habitat sampled together with a small amount of habitat water, and transported to the laboratory. Only 25 samples, out of 78 , were positive for mosquito larvae.

\section{Mosquito identification}

Mosquitoes were identified according to the keys for mosquitoes in the Ryukyu Archipelago (Toma and Miyagi 1986, Tanaka 2003). Adult mosquitoes were identified to species under a stereoscopic microscope. Nonpredaceous larvae were separated by species and placed in white trays $(32.2 \mathrm{~cm} \times 23.1 \mathrm{~cm} \times 5.2 \mathrm{~cm}, 2.8$ liters; Sanbat3gou, Sanko Co.) and reared to 4th instars/adults in the laboratory $\left(27 \pm 1^{\circ} \mathrm{C}\right)$. Approximately half of the 4th instars for each species were preserved in $70 \%$ ethanol. The remaining half were reared to adults. Predaceous Lutzia spp. larvae were separated into individual
Fuji film roll cases $(3 \mathrm{~cm} \times 6 \mathrm{~cm})$ and reared to adults by feeding them with chironomid larvae collected from the same habitat. We did this because Lutzia spp. can only be reliably identified in the adult stage (Bram 1967, Toma and Miyagi 1986). Voucher specimens are preserved in the Museum of Nagasaki University Institute of Tropical Medicine and the Entomological Museum of The Ryukyus University.

\section{Statistical analysis}

We estimated species accumulation curves (SAC) for all samples collected by each method (Gotelli and Colwell 2010, Chaves et al. 2011). A flattening SAC implies a comprehensive sampling of species richness for a given method. We also used the Chao 2 species richness index to estimate the total number of mosquito species (i.e., species richness) by sampling method (Chao et al. 2006, Chaves et al. 2011). For these analyses, we only used data from OTs and LTs given the low number of species collected by NSw and OS. We used the Sørensen index of dissimilarity (beta diversity) to measure the similarity in species composition (Doi and Okamura 2011) across the study sites for OTs, since it was the only method with enough sampling locations warranting a valid analysis. The Sørensen index ranges from 0 to 1 , with higher values indicating a high similarity in species composition. A hierarchical cluster analysis was used to display results from the Sørensen similarity index. For the analyses, we used R (version 3.0.3; Vienna, Austria) and its vegan package (version 2.0-10) and cluster package (version 1.15.2).

\section{RESULTS}

A total of 568 adults and 10,270 larvae, belonging to 6 genera and 13 species, were collected from the 3 habitats surveyed (animal farm, forest, and lake), using 4 mosquito collection methods from April 2007 to March 2008 (Tables 1-4).

Species collection using OTs and LTs were comprehensive as indicated by the flattening SAC curves (Fig. 2). The Chao2 species richness estimate for LTs $( \pm$ SE) was $11.00 \pm 0.01$ and for OTs was $10.00 \pm 3.74$. These estimates were similar to the number of species we found in the field with each method, thus supporting the comprehensiveness of the sample surveys. The heterogeneity of our sampling sites was reflected in the species composition across our sampling locations, showing 2 clusters in LTs (Fig. 3). One of those clusters had a higher species richness (7 versus 8 species) but lower mosquito abundance ( $n=2,299$ versus 7,512). Similarity in species from the forest sites was split between one cluster for the lake area and another for the animal farm 
Table 1. Total number of mosquitoes collected by oviposition traps in 3 different habitats: animal farm, forest, and lake. Two traps were operated in each habitat.

\begin{tabular}{|c|c|c|c|c|c|c|c|}
\hline \multirow[b]{2}{*}{ Species } & \multicolumn{2}{|c|}{ Farm } & \multicolumn{2}{|c|}{ Forest } & \multicolumn{2}{|c|}{ Lake } & \multirow[b]{2}{*}{ Total } \\
\hline & Site 1 & Site 2 & Site 1 & Site 2 & Site 1 & Site 2 & \\
\hline Aedes (Stegomyia) albopictus & 124 & 74 & 287 & 27 & 115 & 252 & 879 \\
\hline Armigeres (Armigeres) subalbatus & 0 & 0 & 0 & 0 & 0 & 56 & 56 \\
\hline Culex (Culex) quinquefasciatus & 0 & 435 & 0 & 0 & 0 & 0 & 435 \\
\hline Cx. (Cux.) tritaeniorhynchus & 18 & 0 & 0 & 0 & 0 & 0 & 18 \\
\hline Cx. (Culiciomyia) pallidothorax & 144 & 316 & 0 & 287 & 302 & 0 & 1,049 \\
\hline Cx. (Cui.) ryukyensis & 15 & 8 & 79 & 89 & 197 & 174 & 562 \\
\hline Lutzia (Metalutzia) fuscana & 10 & 1 & 0 & 0 & 2 & 0 & 13 \\
\hline Lt. (Mlt.) vorax & 71 & 143 & 38 & 91 & 152 & 45 & 540 \\
\hline \multicolumn{8}{|l|}{ Uranotaenia (Pseudoficalbia) } \\
\hline novobscura ryukyuana & 162 & 0 & 2,734 & 284 & 960 & 2,119 & 6,259 \\
\hline Total & 544 & 977 & 3,138 & 778 & 1,728 & 2,646 & 9,811 \\
\hline
\end{tabular}

(Fig. 3). This may reflect the possibility that mosquito fauna at the forest acts as a "source" for most species present in the study area, i.e., larval habitats and species are more diverse in the forest, and then adults from the forest, a habitat "source," disperse into the animal farm and lake area, thus the forest sites clustering between the more different fauna of the lake and the animal farm.

The largest number of species per genus were observed in Culex ( 5 species, $n=2,397$ ), followed by Aedes ( 2 species, $n=1,344)$ and Lutzia (2 species, $n=560$ ), Armigeres ( 1 species, $n=108$ ), Anopheles (1 species, $n=55)$, Uranotaenia (1 species, $n=6,347$ ) and Malaya ( 1 species, $n=22$ ). Uranotaenia novobscura ryukyuana Tanaka, Mizusawa, and Saugstad was the most abundant species, probably reflecting its stable densitydependent abundance (Hoshi et al. 2014). The highest number of mosquitoes were collected using OTs ( $n=9,811,9$ species), and LTs had the richest species composition among the 4 sampling methods ( $n=294,11$ species $)$ used. Two species not collected by LTs were Lt. fuscana (Weidemann), collected by OT, and Ml. genurostris Leicester, collected by OS (Tables 1, 2, and 4).

\section{DISCUSSION}

The mosquito fauna at our study site has not been previously described, but 74 mosquito species have been recorded on the Ryukyu Archipelago (Toma and Miyagi 1986). Okinawa Island has a total of 48 mosquito species (Toma and Miyagi 1986) and 13 (27\%) of these species appeared in our samples. Our mosquito survey was done in south-central Okinawa, where the last entomological survey was conducted $>40$ years ago, using only LTs (Intermill 1967). A comparison between the 2 surveys showed that 8 of the 10 reported species were collected during both studies: Ae. albopictus (Skuse), Ae. vexans nipponii (Theobald), Ar. subalbatus (Coquillett), Anopheles Hyrcanus group, Cx. bitaeniorhynchus Giles, Cx. quinquefasciatus Say, $C x$. tritaeniorhynchus Giles, and Lt. vorax Edwards. Nevertheless, Cx. sitiens (Wiedemann) and Mansonia uniformis (Theobald), commonly found in coastal regions but not alongside lakes (Toma and Miyagi 1986), were not collected, in contrast with the 1967 survey by the US Army (Intermill 1967).

While Ma . uniformis larvae are found attached to emergent vegetation in swamps and lakes

Table 2. Total number of mosquitoes collected by light traps in 2 habitats: animal farm and forest. One trap was placed in each habitat.

\begin{tabular}{|c|c|c|c|c|c|}
\hline \multirow[b]{2}{*}{ Species } & \multicolumn{2}{|c|}{ Farm } & \multicolumn{2}{|c|}{ Forest } & \multirow[b]{2}{*}{ Total (male, female) } \\
\hline & Male & Female & Male & $\overline{\text { Female }}$ & \\
\hline Aedes (Aedimorphus) vexans nipponii & 0 & 26 & 0 & 3 & $29(0,29)$ \\
\hline Ae. (Stegomyia) albopictus & 7 & 22 & 18 & 58 & $105(25,80)$ \\
\hline Armigeres (Armigeres) subalbatus & 14 & 26 & 4 & 0 & $44(18,26)$ \\
\hline Anopheles (Anopheles) Hyrcanus group & 0 & 2 & 2 & 0 & $4(2,2)$ \\
\hline Culex (Oculeomyia) bitaeniorhynchus & 0 & 1 & 0 & 0 & $1(0,1)$ \\
\hline Cx. (Culex) quinquefasciatus & 0 & 0 & 8 & 2 & $10(8,2)$ \\
\hline Cx. (Cux.) tritaeniorhynchus & 0 & 12 & 2 & 1 & $15(2,13)$ \\
\hline Cx. (Culiciomyia) pallidothorax & 0 & 0 & 7 & 0 & $7(0,7)$ \\
\hline Cx. (Cui.) ryukyensis & 0 & 0 & 2 & 0 & $2(0,2)$ \\
\hline Lutzia (Metalutzia) vorax & 1 & 0 & 1 & 3 & $5(2,3)$ \\
\hline Uranotaenia (Pseudoficalbia) novobscura ryukyuana & 12 & 49 & 0 & 11 & $72(12,51)$ \\
\hline Total individuals & 34 & 138 & 44 & 78 & $294(78,216)$ \\
\hline
\end{tabular}


Table 3. Total mosquito species abundance collected by sweep net in 3 different habitats: animal farm, forest, and lake. Each collection was conducted for $10 \mathrm{~min}$.

\begin{tabular}{|c|c|c|c|c|c|c|c|}
\hline \multirow[b]{2}{*}{ Species } & \multicolumn{2}{|c|}{ Farm } & \multicolumn{2}{|c|}{ Forest } & \multicolumn{2}{|c|}{ Lake } & \multirow{2}{*}{$\begin{array}{c}\text { Total } \\
\text { (male, female) }\end{array}$} \\
\hline & Male & Female & Male & Female & Male & Female & \\
\hline Aedes (Stegomyia) albopictus & 7 & 21 & 39 & 126 & 17 & 56 & $266(63,203)$ \\
\hline Armigeres (Armigeres) subalbatus & 0 & 0 & 0 & 3 & 0 & 5 & $8(0,8)$ \\
\hline Total & 7 & 21 & 39 & 129 & 17 & 61 & 274 \\
\hline
\end{tabular}

(Goma 1966, Silver 2008), similar to the lake in our study area, adults of this species were not collected during our study. This may be due to a shift in agricultural production from rice to sugarcane and pineapple, which suggests that environmental changes reduced populations of this species (McDonald and Savage 1972).

Five species had not been previously collected from our study area: $C x$. pallidothorax Theobald, Cx. ryukyensis Bohart, Ur. novobscura ryukyuana, Lt. fuscana, and Ml. genurostris. It is probable that, in addition to environmental changes that might have altered species composition, our diverse and intensive sampling strategy effectively disclosed previously unreported mosquito species in the studied area, since these species have been reported elsewhere in Okinawa (Toma and Miyagi 1986). For example, the detection of $M l$. genurostris was only possible because of larval collections in taro leaf axils, the natural habitat for Malaya spp. (Toma and Miyagi 1986). In addition, the distance of approximately $1.5 \mathrm{~km}$ between ours and the previous sampling site could be another possible explanation for differences in species composition. Although these 2 major differences between the present and past study (i.e., study location and sampling method) made a direct comparison difficult, we believe that our study environment has a richer species composition because of the more heterogeneous environmental setting.

Ecological studies on the Anopheles Hyrcanus group of Okinawa (Rueda et al. 2005, Taira et al. 2012) suggest that the species we found was $A n$. sinsensis Weidemann. The 1 st element to make this suggestion is that, from all the species in the Anopheles Hyrcanus group, only An. lesteri Baisas and $\mathrm{Hu}$ and $A n$. sinensis have been found in Okinawa (Toma and Miyagi 1986, Rueda et al. 2005). These 2 species can be morphologically separated based on the presence of a fringe pale spot in the wings and the presence of abundant scales on the midcoxa (Tanaka et al. 1979, Toma and Miyagi 1986), which according to DNA barcoding are highly precise and accurate identification characters unique to An. sinensis (Taira et al. 2012). Thus, we are certain our samples do not belong to An. lesteri, given the presence of both the fringe pale spot in the wings and abundant scales on the midcoxa of our samples. However, additional molecular tests ( $\mathrm{Li}$ et al. 2005, Rueda et al. 2007) are required to see if our samples

Table 4. Total number of mosquitoes collected by sampling of tree holes, leaf axils, and artificial water containers. Surveys were conducted in the animal farm, forest, and lake habitats.

\begin{tabular}{|c|c|c|c|c|c|}
\hline Species & Site & Date & Larvae & Egg rafts & Habitat \\
\hline Aedes (Aedimorphus) vexans nipponii & Farm & Apr. 1, 2008 & 56 & - & Ground pool \\
\hline \multirow[t]{3}{*}{ Ae. (Stegomyia) albopictus } & Lake & Jun. 15, 2007 & 5 & - & Bamboo \\
\hline & Forest & Oct. 2, 2007 & 1 & - & Garbage can \\
\hline & Farm & Sep. 11,2007 & 3 & - & Water vase \\
\hline \multirow[t]{2}{*}{ Anopheles (Anopheles) Hyrcanus group } & Farm & Sep. 8, 2007 & 25 & - & Water vase \\
\hline & Farm & Sep. 11, 2007 & 26 & — & Water vase \\
\hline \multirow[t]{3}{*}{ Culex (Culex) tritaeniorhynchus } & Farm & Sep. 8, 2007 & 97 & - & Water vase \\
\hline & Farm & Sep. 11,2007 & 186 & - & Water vase \\
\hline & Farm & Feb. 22, 2008 & - & 7 & Water vase \\
\hline Cx. (Culiciomyia) ryukyensis & Forest & Apr. 1, 2008 & 15 & - & Water vase \\
\hline \multirow{2}{*}{ Lutzia (Metalutzia) vorax } & Farm & Sep. 11, 2007 & 2 & - & Water vase \\
\hline & Farm & Feb. 22,2008 & - & 4 & Water vase \\
\hline Uranotaenia (Pseudoficalbia) novobscura & Lake & Jun. 15, 2007 & 16 & - & Bamboo \\
\hline \multirow{7}{*}{ Malaya genuirostris } & Lake & Oct. 13,2007 & 2 & - & Taro leaf axil \\
\hline & Lake & Nov. 3, 2007 & 1 & - & Taro leaf axil \\
\hline & Lake & Nov. 13,2007 & 2 & - & Taro leaf axil \\
\hline & Lake & Dec. 23,2007 & 4 & - & Taro leaf axil \\
\hline & Lake & Jan. 24, 2008 & 6 & - & Taro leaf axil \\
\hline & Lake & Jan. 24, 2008 & 6 & - & Taro leaf axil \\
\hline & Forest & Oct. 1, 2007 & 6 & - & Taro leaf axil \\
\hline
\end{tabular}



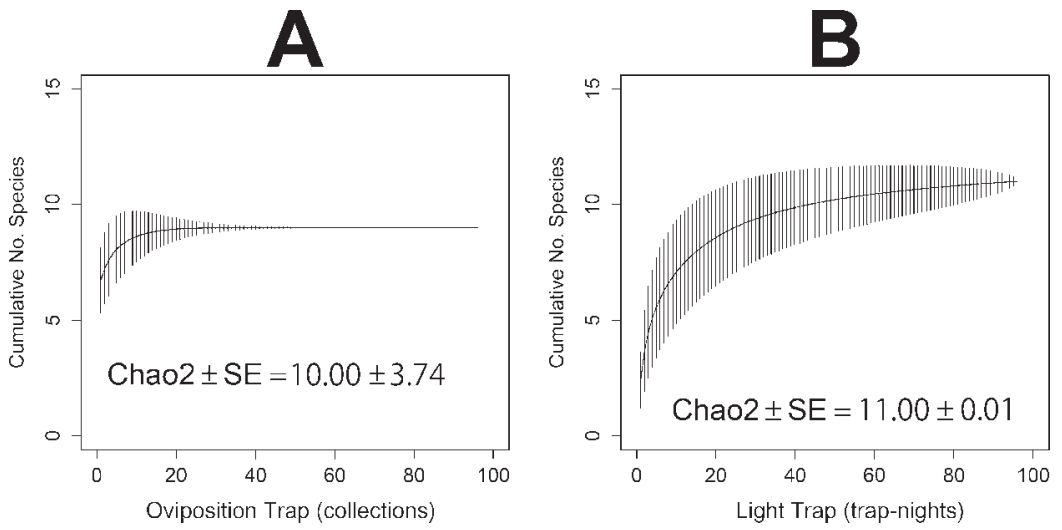

Fig. 2. Mosquito species richness in the south-central part of Okinawa Island. (A) Species accumulation curve (SAC) using ovitraps. The vertical axis shows cumulative number of species and the horizontal axis shows the number of ovitrap collections. (B) SAC using light traps. The vertical axis shows cumulative number of species and the horizontal axis shows the number of collections using light traps.

belong to An. belenrae Rueda, An. kleini Rueda, or An. pullus Yamada, species morphologically indistinguishable from An. sinensis ( $\mathrm{Li}$ et al. 2005), which have not been found in Okinawa (Rueda et al. 2005, Taira et al. 2012).

We collected 6 species that are vectors of medically important pathogens: Ae. albopictus

\section{Height}
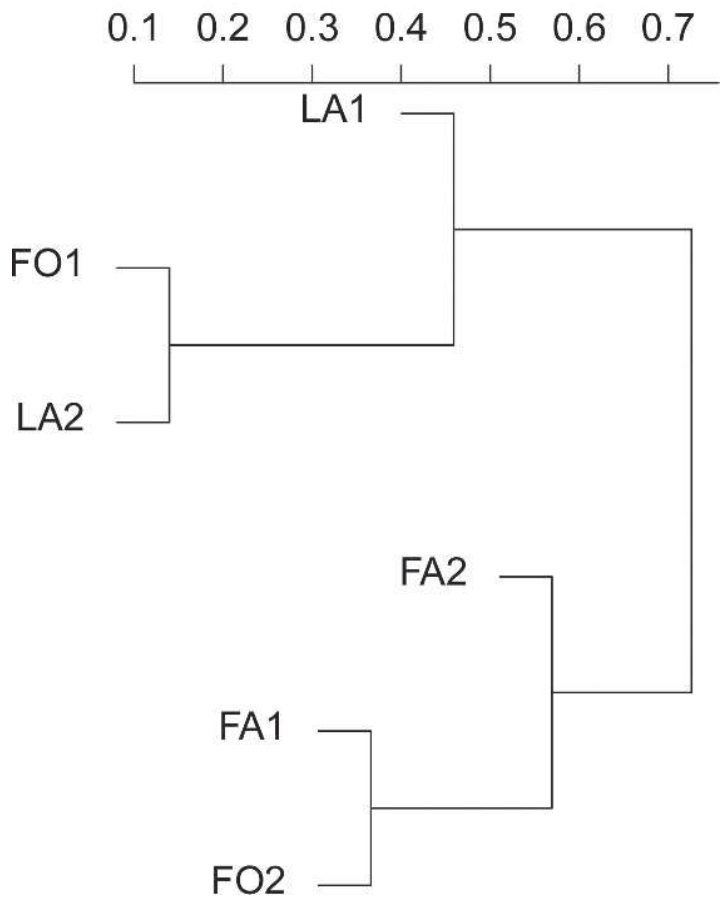

Fig. 3. The multisite Sørensen index of dissimilarity (beta diversity) for ovitraps. In the plot height indicates the difference between sites, i.e., the lower the height the more similar are species between each pair of sites. FO, forest; FA, animal farm; LA, lake. (dengue and chikungunya), Anopheles Hyrcanus group (malaria), Ar. subalbatus (filariasis), $C x$. quinquefasciatus (West Nile, filariasis), Cx. tritaeniorhynchus (Japanese encephalitis), and $C x$. bitaeniorhynchus (filariasis). West Nile, dengue, and chikungunya viruses are potential health threats to Japan (Kasai et al. 2007, Mizuno et al. 2011, Takasaki 2011). The Ryukyu Archipelago, as a subtropical region, is especially vulnerable to vector-borne disease transmission, as has been historically recorded (Miyagi et al. 1996). Therefore, monitoring mosquito biodiversity is an important task in this area. Finally, our results suggest that although LTs sample most of the species in a mosquito community (Brown et al. 2008), only the combination of several sampling methods provides a comprehensive description of a local mosquito faunal composition.

\section{ACKNOWLEDGMENTS}

We thank Ichiro Miyagi (University of Ryukyus) and Takako Toma (University of Ryukyus), who supported study design and implementation, including technical and financial support, and Masako Yafuso (University of Ryukyus) for encouragement throughout the study. Two anonymous reviewers provided valuable comments to improve the manuscript presentation. Junko Sakemoto provided administrative support at Nagasaki University. This study was partially supported by the Nagasaki University Program for Nurturing Global Leaders in Tropical and Emerging Communicable Diseases.

\section{REFERENCES CITED}

Bram RA. 1967. Contributions to the mosquito fauna of southeast Asia-II. The genus Culex in Thailand 
(Diptera: Culicidae). Contrib Am Entomol Inst 2: 1-296.

Brown HE, Paladini M, Cook RA, Kline D, Barnard D, Fish D. 2008. Effectiveness of mosquito traps in measuring species abundance and composition. $\mathrm{J} \mathrm{Med}$ Entomol 45:517-521.

Chao A, Chazdon RL, Colwell RK, Shen TJ. 2006. Abundance-based similarity indices and their estimation when there are unseen species in samples. Biometrics 62:361-371.

Chaves LF, Hamer GL, Walker ED, Brown WM, Ruiz MO, Kitron UD. 2011. Climatic variability and landscape heterogeneity impact urban mosquito diversity and vector abundance and infection. Ecosphere 2:art70.

Chaves LF, Kitron UD. 2011. Weather variability impacts on oviposition dynamics of the southern house mosquito at intermediate time scales. Bull Entomol Res 101:633-641.

Doi H, Okamura H. 2011. Similarity indices, ordination, and community analysis tests using the software R. Jpn J Ecol 61:3-20.

Foley DH, Rueda LM, Wilkerson RC. 2007. Insight into global mosquito biogeography from country species records. J Med Entomol 44:554-567.

Goma LKH. 1966. The mosquito. London, United Kingdom: Hutchinson Tropical Monographs.

Gotelli NJ, Colwell RK. 2010. Estimating species richness. In: Magurran AE, McGill BJ, eds. Biological diversity: frontiers in measurement and assessment. Oxford, United Kingdom: Oxford Univ. Press. p. $39-54$.

Hoshi T, Higa Y, Chaves LF. 2014. Uranotaenia novobscura ryukyuana (Diptera: Culicidae) population dynamics are denso-dependent and autonomous from weather fluctuations. Ann Entomol Soc Am 107:136-142.

Intermill RW. 1967. Distribution and abundance of mosquitoes in Okinawa. Okinawa, Japan: US Army Medical Center, Ryukyu Island.

Kasai S, Shono T, Komagata O, Tsuda Y, Kobayashi M, Motoki M, Kashima I, Tanikawa T, Yoshida M, Tanaka I, Shinjo G, Hashimoto T, Ishikawa T, Takahashi T, Higa Y, Tomita T. 2007. Insecticide resistance in potential vector mosquitoes for West Nile virus in Japan. J Med Entomol 44:822-829.

Li C, Lee JS, Groebner JL, Kim HC, Klein TA, O’Guinn ML, Wilkerson RC. 2005. A newly recognized species in the Anopheles hyrcanus group and molecular identification of related species from the Republic of South Korea (Diptera: Culicidae). Zootaxa 939:1-8.

Makiya K. 1974. Population dynamics of mosquitoes in Nagoya district: B. Larval and imaginal populations of Aedes albopictus (Skuse) in a cemetary of Nagoya City. Japanese Journal of Sanitary Zoology 25:41-49.

McDonald J, Savage L. 1972. Mosquitoes and agriculture on Okinawa. Mosq News 32:466-467.

Miyagi I. 1976. Description of a new species of the genus Topomyia Leicester from the Ryukyu Islands, Japan (Diptera: Culicidae). Trop Med 17:201-210.

Miyagi I, Toma T. 1980. Studies on the mosquitoes in Yaeyama Islands, Japan. 5. Notes on the mosquitoes collected in forest areas of Iriomotejima. Jpn J Sanit Zool 31:81-91.

Miyagi I, Toma T, Malenganisho WL, Uza M. 1996. Historical review of mosquito control as a component of malaria eradication program in the Ryukyu
Archipelago. Southeast Asian J Trop Med Public Health 27:498-511.

Miyagi I, Toma T, Mogi M. 1992. Biological control of container-breeding mosquitoes, Aedes albopictus and Culex quinquefasciatus, in a Japanese island by release of Toxorhynchites splendens adults. Med Vet Entomol 6:290-300.

Miyagi I, Toma T, Ramalingam S. 1990. Topomyia (Topomyia) yongi, a new species of mosquito from peninsular Malaysia (Diptera: Culicidae). Mosq Syst 22:185-191.

Mizuno Y, Kato Y, Takeshita N, Ujiie M, Kobayashi T, Kanagawa S, Kanagawa S, Kudo K, Lim CK, Takasaki T. 2011. Clinical and radiological features of imported chikungunya fever in Japan: a study of six cases at the National Center for Global Health and Medicine. J Infect Chemother 17:419-423.

Nguyen AT, Williams-Newkirk AJ, Kitron UD, Chaves LF. 2012. Seasonal weather, nutrient dynamics and conspecific presence impacts on the southern house mosquito oviposition dynamics in combined sewage overflows. J Med Entomol 49:1328-1338.

NIID [National Institute of Infectious Diseases-Japan]. 2010. NESID annual surveillance data (notifiable diseases) [Internet]. Tokyo, Japan: National Institute of Infectious Diseases [accessed June 16, 2014]. Available from: http://idsc.nih.go.jp/idwr/ydata/reportEa.html.

Okudo H, Toma T, Sasaki H, Higa Y, Fujikawa M, Miyagi I, Okazawa T. 2004. A crab-hole mosquito, Ochlerotatus baisasi, feeding on mudskipper (Gobiidae: Oxudercinae) in the Ryukyu Islands, Japan. J Am Mosq Control Assoc 20:134-137.

Ota H. 1998. Geographic patterns of endemism and speciation in amphibians and reptiles of the Ryukyu Archipelago, Japan, with special reference to their paleogeographical implications. Res Popul Ecol 40:189-204.

Reisen WK, Basio RG. 1972. Oviposition trap surveys conducted on four USAF installations in the western Pacific. Mosq News 32:107-108.

Rueda LM, Iwakami M, O’Guinn M, Mogi M, Prendergast BF, Miyagi I, Toma T, Pecor JE, Wilkerson RC. 2005. Habitats and distribution of Anopheles sinensis and associated Anopheles Hyrcanus group in Japan. J Am Mosq Control Assoc 21:458-463.

Rueda LM, Zhao T, Ma Y, Gao Q, Ding ZG, Khuntirat B, Sattabongkot J, Wilkerson RC. 2007. Updated distribution records of the Anopheles (Anopheles) hyrcanus species-group (Diptera: Culicidae) in China. Zootaxa 1407:43-55.

Silver J. 2008. Mosquito ecology: field sampling methods. 3rd edition. Dordrecht, Netherlands: Springer.

Taira K, Toma T, Tamashiro M, Miyagi I. 2012. DNA barcoding for identification of mosquitoes (Diptera: Culicidae) from the Ryukyu Archipelago, Japan. Med Entomol Zool 63:289-306.

Takasaki T. 2011. Imported dengue fever/dengue hemorrhagic fever cases in Japan. Trop Med Health 39:13-15.

Tanaka K. 2003. Studies on the pupal mosquitoes of Japan (9): genus Lutzia, with establishment of two new subgenera, Metalutzia and Instulalutzia (Diptera, Culicidae). Jpn J Syst Ent 9:159-169.

Tanaka K, Mizusawa K, Saugstad ES. 1979. A revision of the adult and larval mosquitoes of Japan (including the Ryukyu Archipelago and the Ogasa- 
wara Islands) and Korea (Diptera: Culicidae). Contrib Am Entomol Inst 16:1-987.

Thongsripong P, Green A, Kittayapong P, Kapan D, Wilcox B, Bennett S. 2013. Mosquito vector diversity across habitats in central Thailand endemic for dengue and other arthropod-borne diseases. PLoS Negl Trop Dis 7:e2507.

Toma T. 2002. Studies on the Anopheles mosquitoes in the Ryukyu Archipelago, Japan. Med Entomol Zool 53:7-19.

Toma T, Miyagi I. 1986. The mosquito fauna of the Ryukyu Archipelago with identification keys, pupal descriptions and notes on biology, medical importance and distribution. Mosq Syst 18:1-109.

Toma T, Miyagi I, Murakami H, Nerome H, Yonamine M, Higa Y, Tokuyama Y. 2003. Distribution and seasonal prevalence of Anopheles minimus Theobald (Diptera: Culicidae) in the Yaeyama Island group (except Ishigaki Island), Ryukyu Archipelago, Japan, 1999-2000. Med Entomol Zool 54:267-274.

WHO [World Health Organization]. 1975. Manual on practical entomology in malaria. Parts I and II. Geneva, Switzerland: World Health Organization. 